\title{
The extents of metabolic syndrome among Antiretroviral Therapy exposed and ART naïve adult HIV patients in the Gedeo-zone, Southern-Ethiopia: a comparative cross- sectional study
}

\author{
Girma Tenkolu Bune ${ }^{1 *}$, Alemayehu Worku Yalew ${ }^{2}$ and Abera Kumie ${ }^{2}$
}

\begin{abstract}
Background: HIV infection and Antiretroviral Therapy (ART) has been associated with metabolic syndrome (MS). The prevalence of MS varies substantially between populations and is not yet well-known in sub-Saharan Africa (SSA), including Ethiopia. The current study aims to estimate and evaluate the magnitude of MS among ART exposed and ART naïve HIV-infected patients.

Methods: A comparative cross-sectional design was employed among the randomly chosen PLHIVs from two hospitals and two health centers, found in the Gedeo zone, southern-Ethiopia. Data collection was run beginning from December 29th, 2017 up to January 22nd - 2019, using the WHO steep tool; eventually, the completed data entered into Epidata (V-3.1) and exported to SPSS $\left(V^{-22}\right)$ for analysis. The revised international diabetes federation criterion was used to define MS and its components. The mean, standard deviations and proportions were used as a descriptive summary. Categorical data and the proportion of MS in the two groups were compared using binary logistic regression, and results were reported statistically significant with $p$-value is less than $5 \%$.
\end{abstract}

Results: A total of 633 ( $n=422$ on ART and $n=211$ ART-naive) PLHIVS was involved, with an overall response rate of $96.2 \%$. The cumulative proportion of MS was $42.5 \%(95 \% \mathrm{Cl}: 39.2-45.7)$, with $43.4 \%(95 \% \mathrm{Cl}: 39.1-47.4)$ among ART exposed and 40.8\% (95\% Cl: 35.5-46.0) among ART naive patients ( $P>0.005)$. However, the difference was not statistically significant and signified that ART has no association with an increased proportion of MS.

Conclusion: Overall this study demonstrated the presence of an elevated degree of overall MS among PLHIVs. Besides, although the difference was not statistically significant, a relatively higher proportion of MS was realized in the ART exposed than ART nairve groups. Implicated that at the time of the entire test and treatment approaches employed in this target group, routine screening of MS incorporated through HIV care and management system will be a vibrant action.

Keywords: Metabolic syndrome, Human immunodeficiency virus, People living with HIV, Antiretroviral therapy (ART) exposed, ART naïve

\footnotetext{
* Correspondence: girmatenkolu1973@gmail.com

${ }^{1}$ School of Public Health, Dilla University, Dilla, Ethiopia

Full list of author information is available at the end of the article
}

(c) The Author(s). 2020 Open Access This article is licensed under a Creative Commons Attribution 4.0 International License, which permits use, sharing, adaptation, distribution and reproduction in any medium or format, as long as you give appropriate credit to the original author(s) and the source, provide a link to the Creative Commons licence, and indicate if changes were made. The images or other third party material in this article are included in the article's Creative Commons licence, unless indicated otherwise in a credit line to the material. If material is not included in the article's Creative Commons licence and your intended use is not permitted by statutory regulation or exceeds the permitted use, you will need to obtain permission directly from the copyright holder. To view a copy of this licence, visit http://creativecommons.org/licenses/by/4.0/ The Creative Commons Public Domain Dedication waiver (http://creativecommons.org/publicdomain/zero/1.0/) applies to the data made available in this article, unless otherwise stated in a credit line to the data. 


\section{Background}

While global efforts are integrated into the combat against HIV, the prevalence of people living with HIV (PLHIVs) constantly increases due to the rollout of antiretroviral therapy (ART) [1]. In 2018, 23.3 million PLHIVs were accessing ART up from 7.7 million in 2010. As of the end of June 2019, 24.5 million people living with HIV (PLHIVs) were accessing the treatment [2]. This access was complemented with a 51\% reduction in HIV mortality, from 1.95 million in 2006 to 0.95 million in 2017 [3], improved quality of life and survived longer $[4,5]$.

With increased survival, the global morbidity and mortality from infectious diseases have occupied a backseat [6]; instead, non-AIDS comorbidity, like a noncommunicable disease (NCDs), following acquiring its risk marker known as Metabolic Syndrome (MS) has become a worldwide public health issue [6-8]. MS is commonly defined as a constellation of interconnected complex diseases such as abdominal fat, high blood pressure, dyslipidemia, elevated blood sugar $[5,9,10]$. Though not identical, there have been diverse standardized definitions used to diagnose MS [10], each with criteria that influence its diagnosis and complexity $[6,8$, 11-14].

Although much effort on the provision of chronic care has been focused on the control of opportunistic infections [1], not as much care is on the relationship between HIV infection, ART and MS development among PLHIVs [5]. This syndrome was initially recognized in HIV patients a few years after the initiation of ART [6]. Since then, it has imposed countless challenges to the world health designers due to its consequences in various lifestyle diseases [6]. Adult individuals with MS will have 3-times likely to have Cardiovascular Diseases (CVDs) and a 5-fold greater risk of acquiring Type Two Diabetes Mellitus (T2DM) [9, 15-18]. They are nonAIDs associated causes of morbidity and mortality in PLHIVs [1, 4]. For this reason, presently, it is regarded as a newly re-emerging challenge of the PLHIVs population $[9,19]$, in addition to achieving the 90: 90: 90 targets and moving to 'test and treat' [19].

Several works of literature have shown that the overall prevalence of MS risk among PLHIVs is inconsistent and is high $[5,11,14]$, with ranges of $16.7-31.3 \%$ [10]. As well, a narrative review from Africa and a meta-study from the sub-Saharan Africa (SSA) countries reported comparably higher ranges of (13-58\%) (9, 15.1-26.9\%) [5] of MS in PLHIVs, respectively.

Moreover, studies also pinpointed that the mechanisms of MS and its traits among PLHIVs are well predicted and attributed to the HIV infection and the ARV regimen $[1,5,11]$. The MS change begins early in the course of HIV infection [7, 8]. The inflammatory response and cellular apoptosis are the two mechanisms associated with MS development and HIV infection [1]. Even after ART initiation, the number of cytokines (which is a pro-inflammatory agent) in the blood remains higher [6] and the impact on the components of MS is to be more pronounced [6,7]. Overall, the adverse effect of ART causes dyslipidemia, lipodystrophy, and mitochondrial dysfunction side effects, which are implied to initiate body mechanisms that lead to the occurrence of MS [1].

Despite these facts, yet, little is known about the extents of MS and the difference of burden among PLHIVs with or without ART in SSA [5, 14, 20]. Much of studies from resource-rich World primarily noted MS burden among all PLHIVs, regardless of their ART status [5, 10, 21, 22]. Besides, such studies in the same setting are inadequate [14]; particularly, in the era of test and treat and increasing survival due to the treatment effect and epidemiological shifts taking place in the region $[5,14]$. Whether ART exposed to ART naïve individuals have a high risk of MS remains debatable.

Thus, the current study aims to estimate and evaluate the magnitude of MS among ART exposed and ART naïve individuals, by using the revised International Diabetes Federation (IDF) criteria [12]. This manuscript is an extension of a large study with many objectives (of which one article was published [13]). The former and the latter criteria used by the manuscripts are different in various aspects; perhaps, reflecting the dynamic nature of the methods resulted from the aggregate facts of the subject's gathered over time $[6,8,12,13]$.

The study is significant to Ethiopia, including SSA that allows a great dual load following the long-drawn-out epidemiological change. It is a paramount research urgency area, as relevant primary data are limited, particularly in the era of growing access to treatment in the region, including the study country and zone, where the issue has not yet been well addressed, to the best of our knowledge. Besides, initiating such a study has a paramount significance to pave the way to tackle the syndrome among PLHIVs, once for all, in the countries of East African as a whole and Ethiopia, in particular, where they lack contextually developed specific criteria and fully dependent on that standard criterion formed in the western mindset.

\section{Methods and materials Study design}

A comparative crossectional study approach was used.

\section{Study contexts}

Gedeo zone was the place where this study was conducted. It is located $360 \mathrm{KM}$ to the south of Addis Ababa, the main city of Ethiopia. The study was run 
beginning from December 29th, 2017 to January 22nd, 2019. During the study period, as per the Gedio zone ART case team Health Management Information system (HMIS) report, a total of 3597 adult PLHIVs (629 ARTnaive (370 female, 259 male) and 2968 currently on ART (1813 female, 1155 male)) existed in the zone. Of which, while 2922 (1790 female and 1132 male) of them were in the first-line regimen, only 46 (23 female, 23 male) were in the second-line regimen. Among these subjects, while 1892 (135 ART naïve and 537 ART exposed) were enrolled in the ART clinics of health centers, the remaining 2807 (412 ART naïve and 2395 ART exposed) of them were enrolled in the hospitals found in the zone [13]. As per the currently revised national guideline for HIV prevention, Care and Treatment protocol, not all people living with HIV are eligible for ART and have got access to ART immediately [29]. With regards to the ART regimens, it is possible to refer to the guideline cited and the pre-published segments of this article with this citation [13].

\section{Participants}

The study was conducted among PLHIVs took routine service under randomly selected two hospitals and health centers found in the zone. Before recruiting the participants, a survey accompanied by the data logs at the data clerk of the clinics of each health care institution was arranged for a month, to assess the daily/ weekly/monthly patient flow. Using the monthly assessment result, with the employment proportional allocation of a sample size to both comparative groups (ARTexposed and ART naïve), the necessary cases to each health institution for 1 year period was predicted. Lastly, the daily enrollment of participants based on the eligibility criteria was undergone using a consecutive sampling method (Fig. 1).

\section{Sample size determination}

The sample size estimation was made using Openepi version 3.03 software and by taking the following assumptions into account: the two population proportion identified from the previous study done in Hawassa university specialized Hospital, Sothern Ethiopia [23], (P1 $=15.6 \%$ for ART naïve and assuming 13\% difference (i.e. 18.1\% among ARTexposed), with 1:2 ratio of the ART naïve and ARTexposed groups, $95 \%$ confidence interval, $5 \%$ level of significance, and with the power of $90 \%$, the calculated sample size for the ART naive groups became 199. By adding 10\% non-response, overall $657(\mathrm{n} 1=219$ and $\mathrm{n} 2=438)$ HIV positive patients were proposed for the study.

\section{Data collection procedure}

The data collection was accomplished using the validated WHO STEPS instrument version 3.2[30]. It covers three different levels or 'steps' of risk factor assessment: Step 1 (questionnaire), which was essential to gather demographic and behavioral characteristics of the PLHIVs. Step 2 (physical measurements), was employed to build on the core data in step 1 and to determine the proportion of the participants with raised blood pressure, overweight and obesity. The NUTEC BP09 Arm-type Fully Automatic Digital BP Monitor was used to measure blood pressure three times on the left arm of the study participants. A constant tension tape meter was used to measure waist circumference (WC). The 220 SECA scale was used to measure body height and weight, and then the result was used to calculate BMI. Step 3(Biochemical measurements) was used to measure the percentage of respondents with impaired fasting plasma glucose, diabetes, and abnormal lipid level. Laboratory investigation was done sometime after completion of STEPS 1 and 2 of the data collection process, with $8-12 \mathrm{~h}$ overnight fast, by withdrawing of $5 \mathrm{~mL}$ blood. The BS-200E Clinical Chemistry Analyzer was used to analyze biochemical measures to all samples serum collected centrally at Dilla University referral and teaching hospital's clinical Diagnostic Laboratory unit. While the enzymatic colorimetric assay method was used for the measurement of all lipid profiles (i.e. total triglyceride and High-density lipoprotein cholesterol), the glucose level was measured by using the glucose oxidase method.

\section{Outcome variables definition}

Globally there exists a diverse internationally recognized standard criterion to diagnose overall MS $[5,10,13,17$, 23, 24]. This study was defined using the revised International Diabetes Federation (IDF) criterion [12]. It is the most commonly applied criteria to diagnose the cumulative burden of MS among PLHIVs [12]. Based on the new IDF criteria, for a person to be defined as having the condition, he /she must have central obesity (i.e. evaluated from either elevated waist circumference with ethnicity-specific values $(\mathrm{men} /$ women $>94 \mathrm{~cm} / 80 \mathrm{~cm}$ ) or body mass index $>/=30 \mathrm{~kg} / \mathrm{m}^{2}$ ) plus any two of the following four factors: raised triglycerides $(\geq 150 \mathrm{mg} / \mathrm{dL}$ $(1.7 \mathrm{mmol} / \mathrm{L})$ or specific treatment for this lipid abnormality); reduced high-density lipoprotein cholesterol $(<$ $40 \mathrm{mg} / \mathrm{dL} \quad(1.03 \mathrm{mmol} / \mathrm{L})$ in males $<50 \mathrm{mg} / \mathrm{dL} \quad(1.29$ $\mathrm{mmol} / \mathrm{L}$ ) in females or specific treatment for this lipid abnormality); raised blood pressure (BP) (systolic BP $\geq 130$ or diastolic $\mathrm{BP} \geq 85 \mathrm{mmHg}$ or treatment of previously diagnosed hypertension), and raised fasting plasma glucose $(\mathrm{FPG}) \geq 100 \mathrm{mg} / \mathrm{dL}(5.6 \mathrm{mmol} / \mathrm{L})$, or previously diagnosed with diabetes [12].

\section{Data processing and analysis}

Often, after completion of each step of the data collection, the completeness of the tools was checked by the 


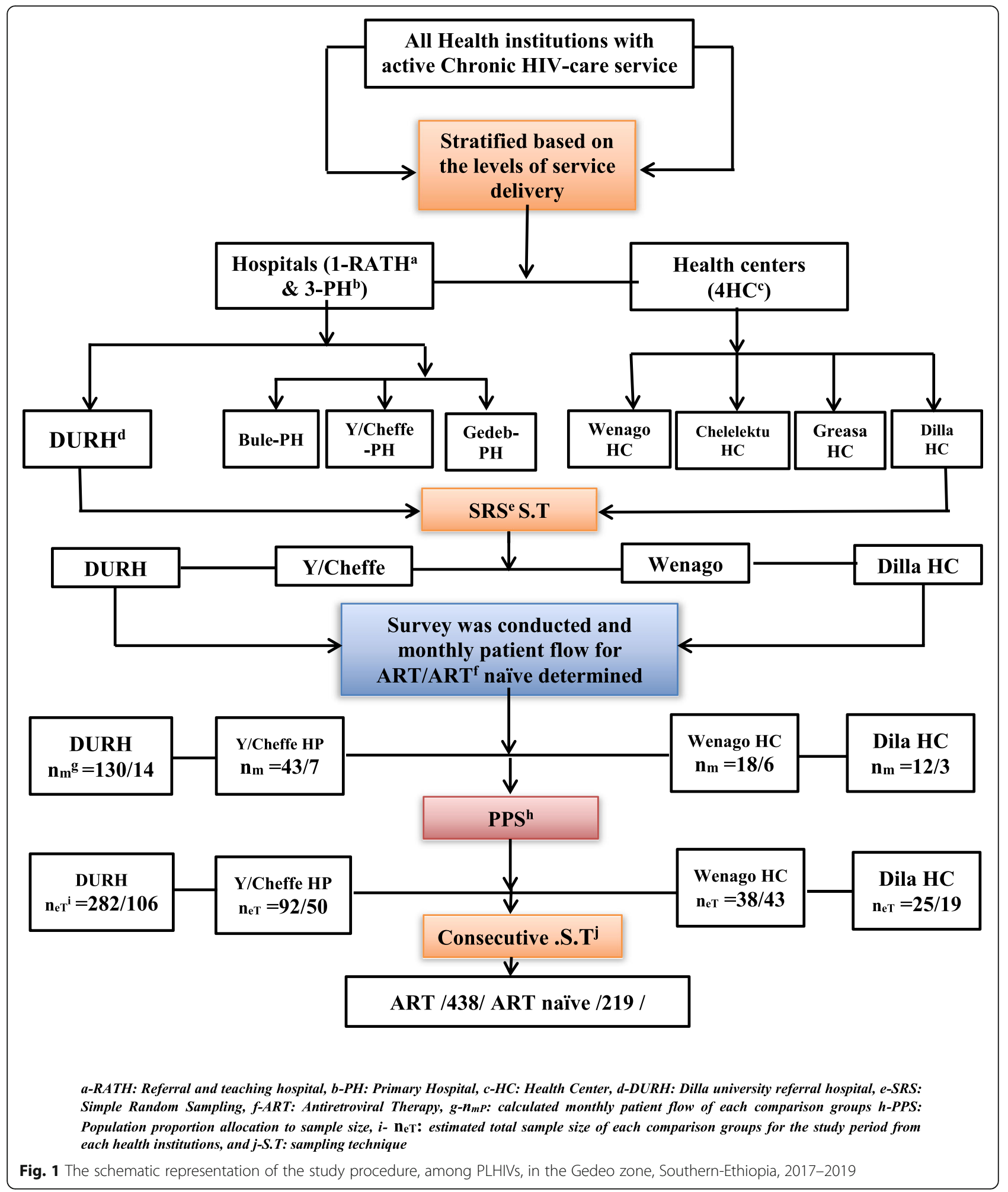

immediate supervisor and the main author. The completed tools entered into a template formed using Epidata version3.1 software by two data clerk; eventually, validation was performed using the original data as references. Subsequently, data were transformed into
Statistical Package for Social Sciences (SPSS) Version 22 for analysis. Statistical analysis was performed by the principal investigator in consultation with the primary and secondary supervisors. Charts were produced using Microsoft ${ }^{\circ}$ Excel 2007. Depending on the scale of the 
variable the mean, standard deviations, and proportions were presented as a descriptive summary. Categorical data and the magnitude of MS in the ART exposed and naïve groups were compared using a binary logistic regression, and results were reported statistically significant whenever the $p$-value is less than $5 \%$.

In light of this, for the rest of the methodological procedure, you can refer to the published paper elsewhere [13].

\section{Ethical clearance}

All the ethical guidelines and principles placed in the Declaration of Helsinki and others, necessary to address the ethical aspects of the research initiated in humans were taken into account. Based on that, the proposal submitted to Addis Ababa University (AAU) College of Health Sciences School of public health Research and Ethics Committee (REC) and then to College of health science Institutional Review Board (IRB) (Meeting No.001/2017 and protocol No.0069/16/SPH) to obtain ethical clearance. Subsequently, the official letter granted from the School of public health by citing the above ethical approval reference number was distributed to the respective Southern Nations Nationalities Regional health bureaus, Gedio zone, and Woreda health bureaus, including to all of the institutions selected to conduct the study. Lastly, to ensure voluntary participation, written consent preceded with oral was attained from each individual.

\section{Result}

\section{The socio-demographic characteristics}

Overall, $633(n=211$ ART-naive and $n=422$ on ART exposed) individuals were participated in the study, with the response rate of $96.2 \%$. More than half (64.1\%)
(69.0\% ART exposed and 54.5\% ART naïve) of the participants were residents of the urban area, and 59.4\% (376) of them were women, with the average age of $(36.4 \pm 8.7)$ years old. Among the 302 participants who were capable of reminding the duration of living with HIV after diagnosis, higher percentage 43.9\% (278) ((58.3\% ART naïve and 36.7\% ART-exposed) of them were reacted that it was lower than a year, with the average duration of $(5.31 \pm 3.99)$ months. Moreover, the result revealed that $53.5 \%(226)$ of women and $46.5 \%$ (196) of men were on either the 1st and 2nd line ART regimen. Of which, nearly 98 of the participant with ART were recalling and guess the time duration since they initiated. Eight point $4 \%$ (7.0\% of men and $9.3 \%$ of women) of these participants were reported to be exposed for about 6 months and below, with the mean reported duration of $5.69 \pm 3.00$ months $(6.27 \pm 3.09$ months for men and $5.31 \pm 2.90$ months for women).

\section{Physical and biochemical measurements}

The mean and standard deviation for each of the physical and biochemical criterion measurements were computed, and the table below summarized the finding as follows (Table 1).

Inline, the study further determined the magnitude of each of the physical and biochemical measured parameters. All in all, the finding designated the presence of an elevated level of each criterion in the ART groups than ART naive, except for the case of BMI and HDL_c. On top of that, excluding for the case of TGL_c and HDL_c, overall the result from the binary logistic regression represented the presence of insignificant differences across the two comparison groups $(P>0.005)$ (Table 2), and (Fig. 2).

Table 1 The mean and standard deviation (SD) of physical and biochemical measurements, by ART status, among PLHIVS, in the Gedeo zone, Southern-Ethiopia, 2017-2019

\begin{tabular}{|c|c|c|c|c|c|c|c|}
\hline \multirow[t]{3}{*}{ S.No } & \multirow[t]{3}{*}{ Criteria } & \multicolumn{4}{|c|}{ ART status } & \multirow{2}{*}{\multicolumn{2}{|c|}{ Total }} \\
\hline & & \multicolumn{2}{|c|}{$\mathrm{ART}^{\mathrm{a}}$ naïve $^{\mathrm{b}}(n=211)$} & \multicolumn{2}{|c|}{ ART exposed $(n=422)$} & & \\
\hline & & Mean & SD & Mean & SD & Mean & SD \\
\hline 1 & Waist circumference (WC) & 83.7 & 8.2 & 83.5 & 7.7 & 83.6 & 7.9 \\
\hline 2 & Body Mass Index (BMI) & 22.22 & 4.36 & 22.18 & 4.54 & 22.19 & 4.48 \\
\hline 3 & Systolic blood pressure (SBP) & 126.9 & 7.8 & 126.9 & 11.5 & 126.9 & 10.4 \\
\hline 4 & Diastolic (DBP) & 82.8 & 5.1 & 83.3 & 6.3 & 83.1 & 5.9 \\
\hline 5 & High-density lipoprotein (HDL_c) & 52.8 & 23.3 & 58.9 & 23.8 & 56.8 & 23.8 \\
\hline 6 & Triglycerides (TGL_C) & 133.5 & 30.2 & 145.9 & 32.3 & 141.8 & 32.1 \\
\hline 7 & Fasting plasma glucose (FPG) & 102.2 & 30.1 & 112.6 & 39.1 & 109.1 & 36.7 \\
\hline 9 & Total cholesterol (TC_C) & 168.9 & 41.0 & 181.5 & 45.2 & 177.3 & 44.2 \\
\hline 10 & Low-density lipoprotein (LDL_c) & 138.4 & 32.7 & 146.6 & 31.9 & 143.9 & 32.4 \\
\hline
\end{tabular}

*SD Standard deviation, ${ }^{\mathrm{a}}$-ART: Antiretroviral Therapy, ${ }^{\mathrm{b}}$-naïve: ART unexposed 
Table 2 Magnitudes of physical and biochemical measures, aggregated by ART status, among PLHIV, in the Gedeo-zone, southernEthiopia, 2017-2019

\begin{tabular}{|c|c|c|c|c|c|c|c|c|}
\hline \multirow[t]{3}{*}{ S.No } & \multirow[t]{3}{*}{ The IDF parameter } & \multicolumn{4}{|c|}{ Magnitude(\%) by ART status } & \multirow{2}{*}{\multicolumn{2}{|c|}{ Total }} & \multirow{3}{*}{$\begin{array}{l}P \text { - } \\
\text { value }\end{array}$} \\
\hline & & \multicolumn{2}{|c|}{ ART naïve $(n=211)$} & \multicolumn{2}{|c|}{ ART exposed $(n=422)$} & & & \\
\hline & & $\%$ & $95 \% \mathrm{Cl}$ & $\%$ & $95 \% \mathrm{Cl}$ & $\%$ & $95 \% \mathrm{Cl}$ & \\
\hline 1 & Raised SBP/DBP $>/=130 / 85 \mathrm{mmHg}^{\mathrm{a}}$ & 54.0 & $47.4-60.2$ & 56.4 & $52.1-61.1$ & 55.6 & $51.8-59.6$ & 0.57 \\
\hline 2 & Raised blood pressure (BP) (SBP/DBP or Anti-HTN treatment user) & 57.3 & $1.0-1.11$ & 56.6 & $1.0-1.07$ & 56.9 & $1.03-1.07$ & 0.87 \\
\hline 3 & Raised $\mathrm{BMI}>/=30 \mathrm{~kg} / \mathrm{M}^{2 \mathrm{~b}}$ & 7.6 & $4.3-10.9$ & 10.9 & $8.1-13.7$ & 9.8 & $7.6-12.2$ & 0.19 \\
\hline 4 & Raised WC (WC > Women 80 or men $>94 \mathrm{~cm})$ & 37.9 & $31.3-44.1$ & 42.2 & $37.7-47.2$ & 40.8 & $37.1-44.5$ & 0.30 \\
\hline 5 & Central Obesity (CO) (WC or BMI) & 42.7 & $37.4-49.3$ & 49.1 & $44.5-53.3$ & 46.9 & $43.3-50.7$ & 0.13 \\
\hline 7 & FPG (FPG > $100 \mathrm{mg} / \mathrm{dl}^{\mathrm{c}}$ or Anti-DM treatment user) & 55.9 & $49.3-62.5$ & 56.4 & $52.1-61.1$ & 56.2 & $52.6-60.0$ & 0.91 \\
\hline 8 & Raised TGL_c (TGL_c>/=150 mg/dl or treated for TGL_c) & 25.6 & $19.9-31.3$ & 42.9 & $37.9-47.4$ & 37.1 & $33.0-40.8$ & $<0.001$ \\
\hline 9 & Low HDL_c (Women< $50 \mathrm{mg} / \mathrm{dl}$ or Men $<40 \mathrm{mg} / \mathrm{dl}$ or treated for TGL_c) & 41.2 & $34.6-47.4$ & 30.8 & $26.3-35.5$ & 34.3 & $30.6-38.1$ & 0.009 \\
\hline
\end{tabular}

${ }^{a}-\mathrm{mmHg}$ : millimeter of mercury, ${ }^{\mathrm{b}}-\mathrm{Kg} / \mathrm{M}^{2}$ : Kilogram per square meter, ${ }^{\mathrm{c}}{ }^{-} \mathrm{mg} / \mathrm{dl}$ : milligram per deciliter.

\section{The magnitude of metabolic syndrome (\%MS)}

The overall proportion of MS was about $42 \%(42.5,95 \%$ CI: 39.2-45.7), with a relatively higher differences being realized in the ART exposed (43.4, 95\% CI, 39.1-47.4) than ART naïve $(40.8,95 \% \mathrm{CI}, 35.5-46.0)$ groups $(p>0.005)$ (Fig. 3). However, the observed difference seen across groups was not statistically significant $(\boldsymbol{P}>\mathbf{0 . 0 0 5})$ (Table 3$)$.

On top of that, for the descriptive purposes, this study furthermore assessed the percentage contribution of each of the parameters in the diagnosis of the burden of MS in both groups and was summarized in Fig. 4 as follows (Fig. 4).

\section{Discussion}

Overall, this study demonstrated the presence of an elevated degree of MS among PLHIVs. Even if the differences were not significant, a relatively higher proportion of MS was realized in the ART exposed (43.4\%) than ART naïve (40.8\%) counter groups. Furthermore, the study revealed that elevated WC contributed to the highest proportion, followed by elevated blood pressure measures, impaired fasting plasma glucose, raised triglycerides, low HDL_c and body mass index.

In contrast to our finding, a narrative review from different African countries by Husain et al. (2017) and the study from Southwestern Uganda by Muyanja et al. (2016) were reported relatively higher magnitude of MS renges (13$58 \%) 9[9,25]$. A recent crossectional study from Ethiopia by G.T. Bune et al. (2019) (22.0, 95\% CI: 19.0-25.4)) [13], by Hirgo.et al. (2016) (24.3\%) [20], by Tesfaye et al. (2014) (25\%) [21] and Berhane T, et al. (2012) (21.1\%) [26], a meta-study from the SSA, by Todowede et al. (2019) (21.5, 95\%CI: 15.09-26.86)) [5] and by Nguyen KA, et al. (2016) worldwide (24.6-31.3\%) [10] were reported lower proportion of MS burden among PLHIVs as a whole, regardless of their ART status. The difference might be partly associated with the difference of sample size used,

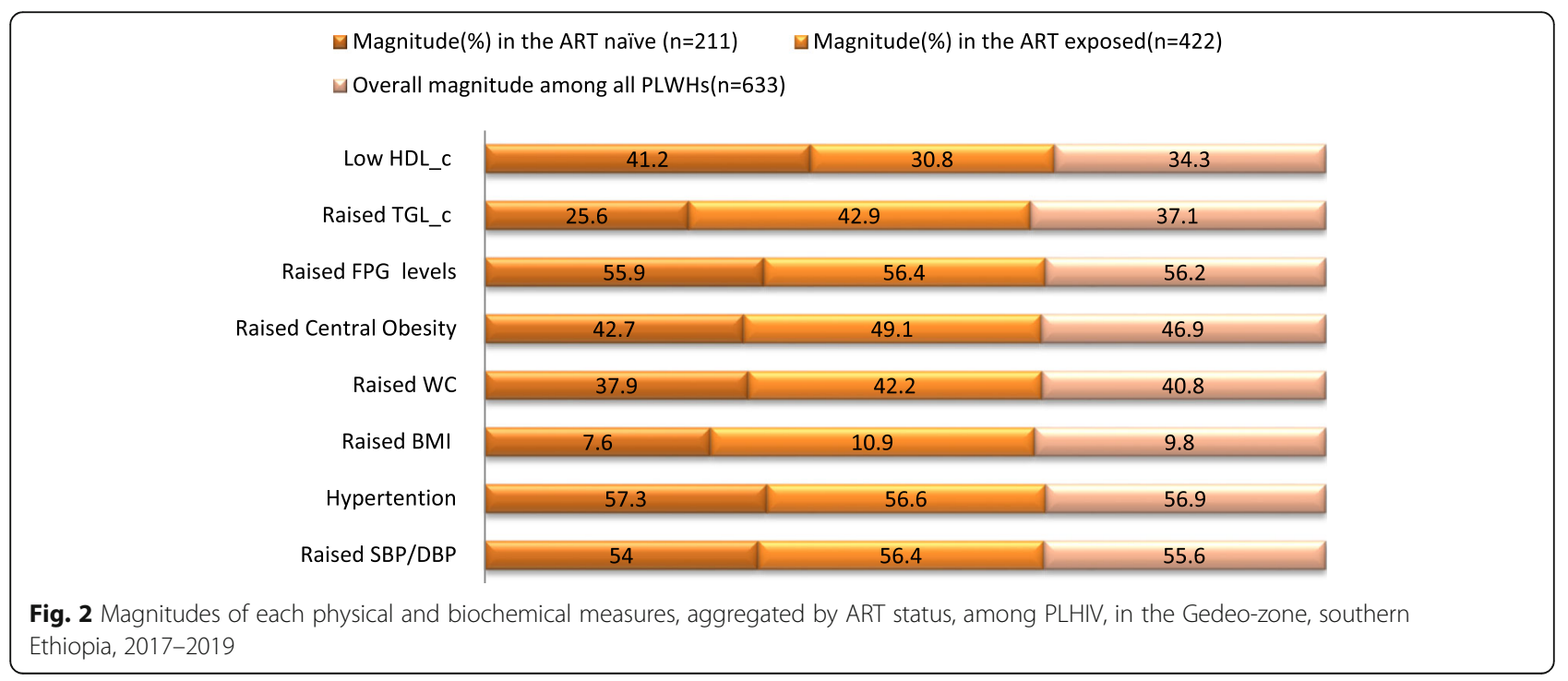




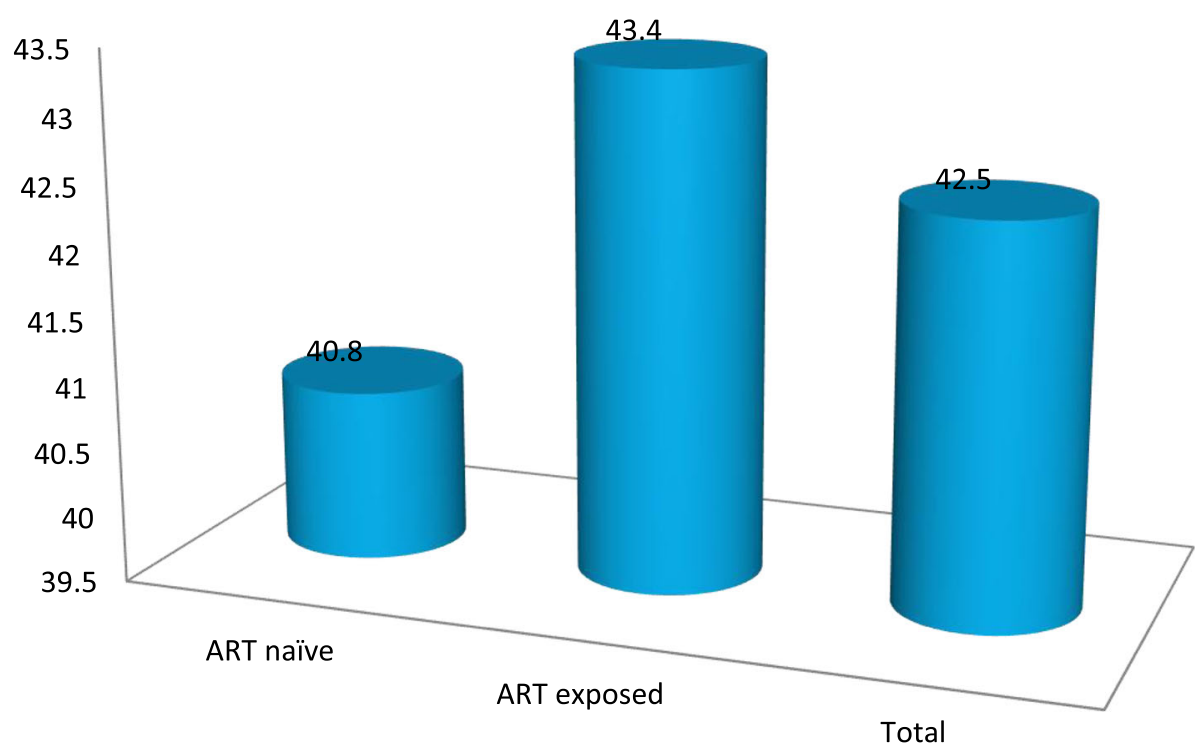

Elevated Magnitude of metabolic syndrome(\%MS)

Fig. 3 The magnitude of metabolic syndrome (MS) by ART status, in the Gedeo zone, southern-Ethiopia, 2017-2019

the overlapping of the host, the virus and/or the type of ART regimen related differences $[5,7,10,17,20]$.

Further, our study has highlighted the presence of a higher magnitude of MS in the ART exposed groups than the ART naïve; however, the observed difference was not statistically significant, $(P>0.005)$. Analogs with the finding, a narrative review in the globe designated the presence of differences of extents of MS among ART exposed and unexposed individuals, with a relatively higher range of (18.4-21.6\% ART exposed vs.11.8-19.9\% ART naïve) MS magnitude [5, 7, 10, 17, 20]. Specifically, for example, a study by G.T. Bune et al. (2019) (22.5, 95\% CI: 18.7-26.8 ART exposed vs. 20.9, 95\% CI: $15.2-$ 27.1 ART naïve, $P>0.05)$ [13], a meta-analysis study in the globe $(18.4,95 \% \mathrm{CI}: 15.9-21.1$ in the ART-exposed and 11.8, 95\%CI: 9.3-14.7, in the ART-naïve $p=0.001$ ) [10] were also revealed same. However, the proportion reported to both groups was inconsistent and was below

Table 3 Magnitude of metabolic syndrome (\%MS), among PLHIVSs, in the Gedeo-zone, southern-Ethiopia, 2017-2019

\begin{tabular}{|c|c|c|c|c|c|}
\hline \multirow[t]{2}{*}{ S.no } & \multirow[t]{2}{*}{ Factors } & \multirow[t]{2}{*}{$\mathbf{n}$} & \multicolumn{2}{|c|}{ Elevated Magnitude of metabolic syndrome(\%MS $\left.{ }^{\mathrm{a}}\right)$} & \multirow[t]{2}{*}{$P$-value } \\
\hline & & & $\%(95 \% \mathrm{Cl})^{\mathrm{b}}$ & OR $(95 \% \mathrm{Cl})^{c}$ & \\
\hline \multirow[t]{3}{*}{1} & ART status & 633 & & & \\
\hline & ART naïve & 211 & $40.8(35.5-46.0)$ & 1 & \\
\hline & ART exposed & 422 & $43.4(39.1-47.4)$ & $1.3(0.9-1.9)$ & .247 \\
\hline \multirow[t]{4}{*}{2} & Age groups in years & 633 & & & \\
\hline & $</=34$ & 315 & $24.4(19.4-28.9)$ & 1 & \\
\hline & $35-44$ & 203 & $54.7(48.3-61.1)$ & $4.6(3.0-7.1)$ & $<0.001$ \\
\hline & $>/=45$ & 115 & $70.4(61.7-78.3)$ & $8.4(5.0-14.2)$ & $<0.001$ \\
\hline \multirow[t]{3}{*}{2} & Sex & 633 & & & \\
\hline & Men & 257 & $21.8(16.7-26.8)$ & 1 & \\
\hline & Women & 376 & $56.6(52.1-61.2)$ & $5.24(3.5-7.8)$ & .000 \\
\hline \multirow[t]{4}{*}{3} & Residents & 633 & & & \\
\hline & Urban & 406 & $46.8(41.9-51.5)$ & 1 & \\
\hline & Rural & 227 & $34.8(28.6-41.4)$ & $0.7(0.5-1.0)$ & .078 \\
\hline & Total & 633 & $42.5(39.2-45.7)$ & & \\
\hline
\end{tabular}




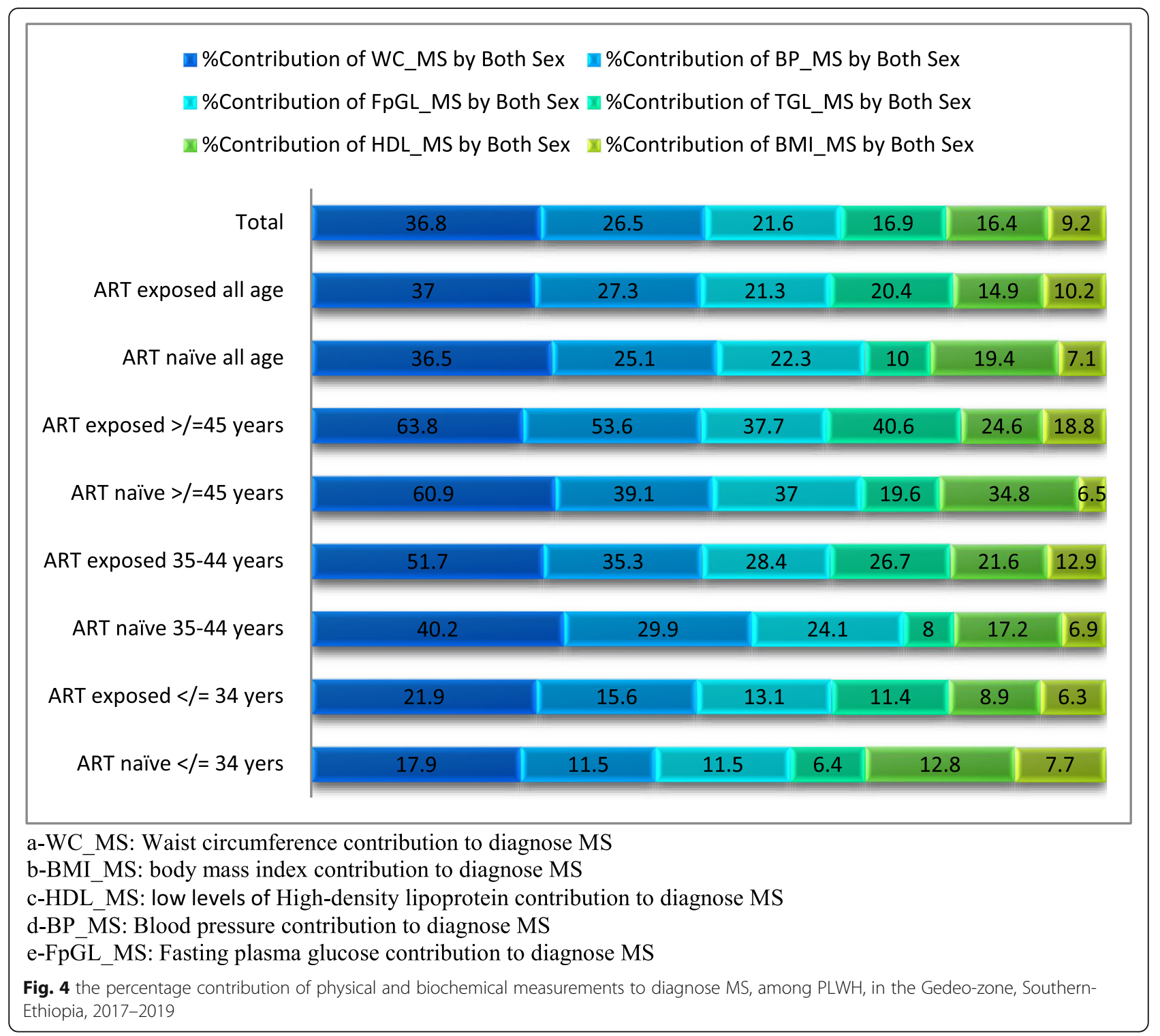

the reported levels of the present study. Regardless of the risk of differences of MS among the two groups in our study result not being significant, it is key that the magnitude of MS in both comparative subjects is raising and ranged in the estimated level of the SSA region. This denotes that the extent of MS is on the rise intensely in PLHIVs with or without ART in the study zone. Implicated that extra factors such as aging, diets, and other lifestyles, associated factors require vital attention other than HIV infection and ART [5].

Also, in contrary to our result, a study from Cameroon by Ngatchou W, et al. (2013) was presented a lower rate of MS in the ART-exposed (21\%), and an extremely higher magnitude of MS in the ART naïve groups (47\%) [27]. The time variation, the number of study participants, the differences in study approaches, and the socio-economic and cultural factors associated with the host could be partially credited for the above differences observed by the studies.

In addition to the above reasoning, the discrepancy may be partly attributed to the various criteria employed by the studies [5]. With this regard, the recent study by G.T. Bune et al. (2019) [13] can be taken as a typical example. As it has been presented elsewhere, the data source for the current and the previously published article was the same. However, the results were inconsistent, and this might be explained due to the difference in standard criteria employed by the studies. Similarly, empirical evidence from several works of literature was unpacking facts that support the above concept. In this regards, for example, a meta-study by Nguyen KA, et al. (2016) was shown distinction of MS burden among 
similar groups based on the difference of standard criteria used (i.e. in the ART-exposed, by (IDF criteria 19.6, 95\%CI: $14.2-25.6$ vs. the ATP III criteria 21.6 , 95\%CI: $13.5-31.014 .9 \%$ ), and in the ART-naïve, by (IDF criteria 14.9, 95\%CI: $8.6-22.6$ vs. the ATP III criteria 19.9, 95\%CI: 18.3-21.5) [10]. Moreover, a study by Tesfaye et al. (2014) shown variations (in the ART exposed, by (IDF criteria $25 \%$ vs. ATP III 18.1\%) and in the ART naïve, by (IDF, 22.6 vs. ATP III 15.6\%) [21]. As it is presented in the literature above, even if there were no reliable differences of MS estimates in between the IDF and ATP III criteria. However, the overall situation underscored the presence of a higher estimation of MS by the IDF criteria in both ART exposed and ART nave groups. This is comparable with our study finding that higher estimates based on the IDF criteria. This indicates a greater waist circumference (WC) in both exposed and unexposed groups enrolled in the study, particularly women, as this is a mandatory condition by IDF criteria $[5,20]$. It was comparable with the report highlighting elevated central obesity based on the WC and BMI score in PLHIVs individuals, particularly in the ART exposed group [20]. This implicated the need for further study to explore the dissimilarity in WC based on ART status. Moreover, it also implicates the critical significance of establishing harmonized standard criteria, which is to be generated in the East-African countries' contexts in general and in the Ethiopia perspective, in particular, to resolve the problem arises from the use of the available standard criterion constructed in the western mindset.

Last, of all, this study has to have several limitations, all of which were inherited from the nature of crossectional study design, institution-based studies, and interviewer assisted data collection methods used. This study also not free from the social desirability bias, and recall biases arose from the individual seeking further medical care, and from inquiring of participants about past experiences, respectively. Besides, it has limitations related to the consideration of relatively fewer men and ART-naïve participants, and the absence of an HIV-negative sub-groups that might potentially affect external validity was the finding.

\section{Conclusion}

Generally, this study demonstrated the presence of an elevated degree of MS among PLHIVs. Also, even if the diffrence was not significant, a relatively higher proportion of MS was realized in the ART exposed than ART naive groups. This signifies the existence of HIV associated MS that necessitates immediate prevention and management strategies in such a resource-restricted area. On top of that, at the time of the entire test and treatment plan of action among HIV infected patients, routine follow-up of MS encompassed through the whole management system is to be a vibrant action.

\section{Abbreviations}

AIDS: Acquired Immunodeficiency syndrome; ART: Antiretroviral Therap; CVD: Cardio Vascular Disorder; HDL_c: High-Density Lipoprotein Cholesterol; IRB: Institutional Review Board; LDL-C: Low-Density Lipoprotein Cholesterol.; MS: Metabolic Syndrome; NCDs: Non-communicable disease; NCEP/ATPIII: National cholesterol Education program adult treatment panel three; NRTI: Nucleosides reverse transcriptase inhibitors; NNRTI: Non-Nucleosides Reverse Transcriptase Inhibitors; PI: Protease inhibitors; PLHIVS: People Living with HIV; 3TC: Lamuvidine; ABC: Abacavir; AZT/ZDV: Zidovudine; EFV: Efavirenz; LPV/r: Ritonavir boosted/ Lopenavir; NFV: Nelfinavir; NVP: Nevirapine; DDI: Didanosine; ATV/r: Ritonavir boosted/ Atazanavir; DRV/ r: Ritonavir-boosted/ Darunavir

\section{Acknowledgments \\ My appreciation goes to Addis Ababa University and Dilla University for their financial support. I also would like to thank Dilla University College of medicine and health science, Yirga-Cheffe town administration health office, Wonago district health office, Dilla Town administration health office, Dilla University Referral Hospital, Yirga-Cheffe hospital, Wonago and Dilla town health center staffs, for their unreserved facilitation on the data collection. On top of that my deepest gratitude also sends to the whole study participants for their cooperation to take part in this study.}

\section{Authors' contributions}

Girma Tenkolu (GT): Conceptualization study idea, Data collection, analysis, result writing, editing, Investigation, Methodology development, Project administration, Resources allocation, Software application, and Supervision. Alemayehu Worku (AW): Conceptualization of study concept, result editing, Investigation, Methodology development, administration, Supervision, journal selection. Abera Kumie (AK): Conceptualization of concept, result editing, Investigation, Methodology development, Project administration, Supervision, journal selection. The author(s) read and approved the final manuscript.

\section{Funding}

This work was supported by Addis Ababa University, Ethiopia and Dilla University, Ethiopia for the partial fulfillment of Ph.D. in public health.

\section{Availability of data and materials}

All data generated or analyzed during this study are included in this published article [and its supplementary information files].

\section{Ethics approval and consent to participate}

All the ethical guidelines and principles placed in the Declaration of Helsinki and others, necessary to address the ethical aspects of the research initiated in humans were taken into account. Based on that, the proposal submitted to Addis Ababa University (AAU) College of Health Sciences School of public health Research and Ethics Committee (REC) and then to College of health science Institutional Review Board (IRB) (Meeting No.001/2017 and protocol No.0069/16/SPH) to obtain ethical clearance. Subsequently, the official letter granted from the School of public health by citing the above ethical approval reference number was distributed to the respective Southern Nations Nationalities Regional health bureaus, Gedio zone, and Woreda health bureaus, including to all of the institutions selected to conduct the study. Lastly, to ensure voluntary participation, written consent preceded with oral was attained from each individual.

\section{Consent for publication}

Not applicable.

\section{Competing interests}

I confirm that there are no competing interests in this research work.

\section{Author details}

${ }^{1}$ School of Public Health, Dilla University, Dilla, Ethiopia. ${ }^{2}$ Schools of Public Health, Addis Ababa University/AAU, Addis Ababa, Ethiopia. 
Received: 9 October 2019 Accepted: 14 April 2020

Published online: 07 May 2020

\section{References}

1. Masuku SKT-GJ, Satorious B. HIV and antiretroviral therapy -induced metabolic syndrome in people living with HIV and its implication for care: a critical review. J Diabetol. 2019;10:41-7.

2. UNAIDS. Global HIV \& AIDS statistics - 2019 fact sheet avaialble at http://www unaids.org/sites/default/files/media_asset/UNAIDS_FactSheet_en.pdf. 2019.

3. Pandey A, Galvani AP. The global burden of HIV and prospects for control. Lancet HIV. 2019:6(12):e809-11.

4. Han WM, Jiamsakul A, Kiertiburanakul S, Ng OT, Sim BL, Sun LP, et al. Diabetes mellitus burden among people living with HIV from the AsiaPacific region. J Int AIDS Soc. 2019;22(1):e25236.

5. Todowede OO, Mianda SZ, Sartorius B. Prevalence of metabolic syndrome among HIV-positive and HIV-negative populations in sub-Saharan Africa-a systematic review and meta-analysis. Syst Rev. 2019:8(1):4.

6. Swami A. Metabolic syndrome and HIV infection. J HIV Retro Virus. 2016;2(1):9.

7. Willig AL, Overton ET. Metabolic complications and glucose metabolism in HIV infection: a review of the evidence. Curr HIV/AIDS Rep. 2016;13(5):289-96.

8. Paula AA, Falcao MC, Pacheco AG. Metabolic syndrome in HIV-infected individuals: underlying mechanisms and epidemiological aspects. AIDS Res Ther. 2013;10(1):32

9. Husain NE, Noor SK, Elmadhoun WM, Almobarak AO, Awadalla H, Woodward CL, et al. Diabetes, metabolic syndrome and dyslipidemia in people living with HIV in Africa: re-emerging challenges not to be forgotten. HIV/AIDS (Auckl). 2017;9:193-202.

10. Nguyen KA, Peer N, Mills EJ, Kengne AP. A Meta-Analysis of the Metabolic Syndrome Prevalence in the Global HIV-Infected Population. PLoS One. 2016;11(3):e0150970

11. Todowede $\mathrm{OO}$, Sartorius B. Prevalence of metabolic syndrome, discrete or comorbid diabetes and hypertension in sub-Saharan Africa among people living with HIV versus HIV-negative populations: a systematic review and meta-analysis protocol. BMJ Open. 2017:7(7):e016602

12. International diabetes federation. The IDF consensus worldwide definition of the metabolic syndrome2017.https://www.idf.org/e-library/consensusstatements/60-idfconsensus-worldwide-definitionof-the-metabolic-syndrome

13. Bune GT, Yalew AW, Kumie A. The global magnitude of metabolic syndrome among antiretroviral therapy (ART) exposed and ART-naïve adult HIV-infected patients in gedio-zone, southern Ethiopia: Comparative crosssectional study,using the Adult Treatment Panel III criteria. Diabetes Metab Syndr. 2019;13(2019):2833-41.

14. Bosho DD, Dube L, Mega TA, Adare DA, Tesfaye MG, Eshetie TC. Prevalence and predictors of metabolic syndrome among people living with human immunodeficiency virus (PLWHIV). Diabetol Metab Syndr. 2018;10:10.

15. Ekrikpo UE, Akpan EE, Ekott JU, Bello AK, Okpechi IG, Kengne AP. Prevalence and correlates of traditional risk factors for cardiovascular disease in a Nigerian ARTnaive HIV population: a cross-sectional study. BMJ Open. 2018;8(7):e019664.

16. Kiama CN, Wamicwe JN, Oyugi EO, Obonyo MO, Mungai JG, Roka ZG, et al. Prevalence and factors associated with metabolic syndrome in an urban population of adults living with HIV in Nairobi, Kenya. Pan Afr Med J. 2018:29:90.

17. Rogalska-Plonska M, Grzeszczuk A, Rogalski P, Lucejko M, Flisiak R. Metabolic syndrome in HIV infected adults in Poland. Kardiol Pol. 2018;76(3):548-53.

18. Hugo Ribeiro Zanetti LR, Gonçalves A. Elmiro Santos Resende, Universidade Federal de Uberlândia (UFU) U, MG - Brazil. Cardiovascular Complications of HIV. Int J Cardiovasc Sci. 2018;31(5):538-43.

19. Smit M, Olney J, Ford NP, Vitoria M, Gregson S, Vassall A, et al. The growing burden of noncommunicable disease among persons living with HIV in Zimbabwe. AIDS. 2018;32(6):773-82

20. Hirigo AT, Tesfaye DY. Influences of gender in metabolic syndrome and its components among people living with HIV virus using antiretroviral treatment in Hawassa, southern Ethiopia. BMC Res Notes. 2016:9(1):145.

21. Tesfaye DY, Kinde S, Medhin G, Megerssa YC, Tadewos A, Tadesse E, et al. Burden of metabolic syndrome among HIV-infected patients in southern Ethiopia. Diabetes Metab Syndr. 2014;8(2):102-7

22. Osoti A, Temu TM, Kirui N, Ngetich EK, Kamano JH, Page S, et al. Metabolic syndrome among antiretroviral therapy-naive versus experienced HIVinfected patients without preexisting Cardiometabolic disorders in Western Kenya. AIDS Patient Care STDs. 2018 Jun;32(6):215-22.
23. Yu B, Pasipanodya E, Montoya JL, Moore RC, Gianella S, McCutchan A, et al. Metabolic Syndrome and Neurocognitive Deficits in HIV infection. J Acquir Immune Defic Syndr. 2019;81(1):95-101.

24. Zicari S, Sessa L, Cotugno N, Ruggiero A, Morrocchi E, Concato C, et al. Immune activation, inflammation, and non-AIDS co-morbidities in HIVinfected patients under long-term ART. Viruses. 2019;11(3):200.

25. Muyanja D, Muzoora C, Muyingo A, Muyindike W, Siedner MJ. High prevalence of metabolic syndrome and cardiovascular disease risk among people with HIV on stable ART in southwestern Uganda. AIDS Patient Care STDs. 2016;30(1):4-10.

26. Berhane T, Yami A, Alemseged F, Yemane T, Hamza L, Kassim M, et al. Prevalence of lipodystrophy and metabolic syndrome among HIV positive individuals on highly active anti-retroviral treatment in Jimma, South West Ethiopia. Pan Afr Med J. 2012;13:43.

27. Ngatchou W, Lemogoum D, Ndobo P, Yagnigni E, Tiogou E, Nga E, et al. Increased burden and severity of metabolic syndrome and arterial stiffness in treatment-naive HIV+ patients from Cameroon. Vasc Health Risk Manag. 2013;9:509-16.

\section{Publisher's Note}

Springer Nature remains neutral with regard to jurisdictional claims in published maps and institutional affiliations.
Ready to submit your research? Choose BMC and benefit from:

- fast, convenient online submission

- thorough peer review by experienced researchers in your field

- rapid publication on acceptance

- support for research data, including large and complex data types

- gold Open Access which fosters wider collaboration and increased citations

- maximum visibility for your research: over $100 \mathrm{M}$ website views per year

At BMC, research is always in progress.

Learn more biomedcentral.com/submissions 